\title{
ROLE OF VARENICLINE IN SMOKING CESSATION: INDIAN SCENARIO
}

Basudev Lenka ${ }^{1}$

\section{HOW TO CITE THIS ARTICLE:}

Basudev Lenka. "Role of Varenicline in Smoking Cessation: Indian Scenario". Journal of Evolution of Medical and Dental Sciences 2014; Vol. 3, Issue 18, May 05; Page: 4940-4943, DOI: 10.14260/jemds/2014/2535

ABSTRACT: Tobacco smoking is one of the leading causes of worldwide morbidity as well as mortality which are largely preventable. Smoking cessation, though a difficult task to achieve, can lead to both immediate and long term health benefits such as reduction of the risk of lung cancer, chronic lung disease, stroke etc. This article reviews the various pharmacological interventions of smoking cessation like nicotine replacement therapy (NRT), bupropion, and nortryptiline etc., especially the role of a novel agent Varenicline in reducing nicotine dependence as well as in decreasing craving after nicotine withdrawal that holds promising effectiveness in Indian scenario.

KEYWORDS: Varenicline, smoking cessation, nicotine, NRT, bupropion.

INTRODUCTION: India is the $3^{\text {rd }}$ largest producer and consumer of tobacco in the world. ${ }^{1}$ Besides cigarettes, Indians also smoke bidis, along with use of smokeless tobacco like gutkha and khaini. Smoking is a high risk factor for coronary heart disease, chronic obstructive pulmonary disease, lung cancer and various other health related problems. The composition of tobacco smoke is complex, but it chiefly contains nicotine and tars, among them nicotine is the main active substance of tobacco products responsible for the positive reinforcements in humans. Chronic use of tobacco causes physical dependence.

Currently, pharmacotherapies for smoking cessation are either nicotine replacement therapy (NRT) by patch, gum, lozenge etc. or bupropion, nortryptiline and clonidine. ${ }^{2}$ But even these treatment options were found to be in efficacious in many cases that were associated with relapse after successful smoking cessation. In this connection, Varenicline, a novel drug that acts as a partial agonist at the nicotinic cholinergic receptor holds particular importance in smoking cessation. In various studies Varenicline has been shown to be more efficacious than other forms of pharmacotherapy like NRT or bupropion, well tolerated among smokers, good safety profile and having virtually no drug interactions.

MATERIALS AND METHODS: A primary literature review was conducted, consisting of a PUBMED database search of English language articles using the keywords Varenicline, smoking cessation, and partial agonist alpha4beta2 nicotinic cholinergic receptor. The bibliographies of these articles were also reviewed for inclusion of additional studies and abstracts not included in the PUBMED search.

VARIOUS SMOKING CESSATION APPROACHES IN INDIA: A number of effective pharmacological methods to quit smoking are widely popular, namely:

A) Nicotine Replacement Therapy (NRT): The principal aim of NRT is to temporarily replace the nicotine from cigarettes to reduce both motivation to smoke and nicotine withdrawal symptoms or cravings. NRTs do not produce the same peak levels of nicotine in blood as with cigarettes and thus do not cause the subjective effects. However they effectively suppress the nicotine withdrawal symptoms. Various forms of NRTs like chewing gum, transdermal patch, inhalers, lozenge and 
sublingual tablets are widely they are relatively safe to the extent that even combination nicotine therapy can be used. However NRT use in cases of recent myocardial infarction or arrhythmia is contraindicated. ${ }^{1}$

B) Bupropion hydrochloride: The anti-depressant bupropion was the first non-nicotine agent to be used as a form of pharmacotherapy in smoking cessation. It is an inhibitor of dopamine and noradrenaline reuptake receptors, which accounts largely for its anti-depressant effects. It also appears to be a weak antagonist of nicotinic receptors. The mechanism of action of bupropion in smoking cessation is not clear, but may involve central adrenergic and dopaminergic systems. ${ }^{2}$ The side effects of bupropion include agitation, anxiety and insomnia. Other less frequently reported side effects are fever, dry mouth, allergic reactions, increased risk of seizure disorders. As with many other anti-depressant drugs, the prescribing information for bupropion carries a black- box warning based on observations that anti-depressants have increased suicidal tendencies in children and adults with certain psychiatric disorders. ${ }^{3}$

\section{C) Newer Treatment Options for Smoking Cessation:}

1. Rimonabant: Rimonabant is a selective cannabinoid receptor antagonist which blocks the CB-1 receptor. In human studies, it has shown beneficial effects in the treatment of smoking cessation and obesity.4, 5 It also regulates endocannabinoid system and reduces craving for nicotine, thereby maintaining abstinence.

2. Topiramate: This anti-epileptic drug is an antagonist of AMPA/ kainate system of central nervous system neurotransmitters and has potential benefits in smoking cessation. ${ }^{6}$

3. Nortryptiline: It is an active and potent metabolite of amitryptiline. Various clinical trials suggest that nortryptiline causes prolonged abstinence rates compared to placebo group. Most noted adverse effects were dry mouth and sedation. Currently it is widely popular as the first line smoking cessation agent.7-10

4. Nicotine vaccine: It stimulates the development of antibodies specific to nicotine and restricts its entry to brain. These vaccines are important agents for preventing relapse cases following successful smoking cessation. ${ }^{11}$

5. Serotonin enhancing diet: Diets that are rich in serotonin content, like high carbohydrate diet or tryptophan have been shown to cause reduction in negative effects associated with withdrawal symptoms. ${ }^{12}$

6. Mecamylamine: This nicotine antagonistic agent blocks the rewarding effect of nicotine. In most trials a combination of mecamylamine with nicotine patch has been found to be more effective than mecamylamine alone. ${ }^{13}$

Varenicline-Nicotinic Receptor Partial Agonist: Varenicline is a nicotinic receptor partial agonist acting mainly on the $\alpha 4 \beta 2$ subtype of the nicotinic cholinergic receptor. As a partial agonist, it both reduces cravings for smoking and decreases the pleasurable effects of cigarettes and other tobacco products. As such, varenicline has been approved by the FDA in May, 2006 as an agent for use in smoking cessation. 
Mechanism of Action of Varenicline: Varenicline is approved for the treatment of nicotine dependence and withdrawal symptoms seen after smoking cessation. ${ }^{14}$ Varenicline as a partial agonist of $\alpha 4 \beta 2$ nicotinic acetylcholine receptor, through intrinsic activation, results in a moderate increase in dopamine levels in the mesolimbic area of brain. By this mechanism varenicline counterbalances the low dopamine levels encountered during attempts, which are responsible for a relapse. In addition to this, varenicline also prevents binding of nicotine to the receptor to some extent and prevent the rewarding effects of smoking. ${ }^{15}$ Research work done by Foulds also explains the basis of partial agonist of $\alpha 4 \beta 2$ nicotinic acetylcholine receptors in the treatment of nicotine dependence. ${ }^{16}$

Adverse Effects of Varenicline: The most common adverse events reported during the premarketing development of varenicline were nausea, sleep disturbances, constipation, flatulence and vomiting. There are some conflicting reports during post marketing surveillance that the drug brings about neuropsychiatric symptoms like agitation, depression, behavioral change, suicidal ideation, but again none of these has been conclusively established till date. On the brighter side, no significant interaction with any other drugs or any effect on enzyme induction or inhibition has been identified yet. Overall, that makes varenicline a relatively safe drug with few minor side effects which is largely outweighed by its beneficial effects.

CONCLUSION: Smoking is the most important preventable major risk factor for many detrimental health issues like lung cancer, chronic lung disease, cardiovascular disease, peripheral vascular disease etc. In spite of having many pharmacologic as well as non-pharmacologic methods for smoking cessation, it is still a difficult task to achieve, more so because of increased craving and relapse after attempted quitting. Varenicline, due to its unique mechanism of action as a partial agonist of $\alpha 4 \beta 2$ nicotinic acetylcholine receptors, reduces withdrawal symptoms of smoking cessation by maintaining a modest level of dopamine in brain. Additionally, owing to its antagonists the reinforcing effects of smoking during relapse. Thus varenicline today represents itself as a promising alternative on the horizon towards achieving a smoke-free world for better living.

\section{REFERENCES:}

1. Najem B, Houssiere A, Pathak A, Janssen C, Lemogoum D, Xhaet 0 et al. Acute cardiovascular and sympathetic effects of nicotine replacement therapy. Hypertension 2006; 47:1162-7.

2. Glaxo Wellcome Inc. Physicians' desk reference. 52nd ed. Montvale, NJ: Medical economics Co.; 1998.

3. Zyban (bupropion hydrochloride) sustained-release tablets (prescribing information), Research Triangle Park, North Carolina; GlaxoSmithKline, 2005.

4. Mansourati J, Borel ML, Munier S, Guevel- Jointnet AL. Medications in smoking cessation. Presse Med 2005; 34:1331-6.

5. Boyd ST, Fremming BA. Rimonabant-A Selective CB1 Antagonist. Ann Pharmacother 2005; 39:684-90.

6. Khazaal Y, Cornuz J, Bilancioni R, Zullino DF. Topiramate for smoking cessation. Psychiatry Clin Neurosci 2006; 60:384-8. 


\section{REVIEW ARTICLE}

7. Wagena EJ, Knipschild P, Zeegers MP. Should nortriptyline be used as a first-line aid to help smokers quit? Results from a systematic review and meta-analysis. Addiction 2005; 100:31726.

8. Dickerson LM, Carek PJ. Nortriptyline effective for smoking cessation. J Fam Pract 2002; 51: 1008.

9. Wagena EJ, Knipschild P, Zeegers MP. Should nortriptyline be used as a first-line aid to help smokers quit? Results from a systematic review and meta-analysis. Addiction 2005; 100: 317-26.

10. Prochazka AV, Kick S, Steinbrunn C, Miyoshi T, Fryer GE. A randomized trial of nortriptyline combined with transdermal nicotine for smoking cessation. Arch Intern Med 2004; 164: 2229-33.

11. Maurer P, Bachmann MF. Therapeutic vaccines for nicotine dependence. Curr Opin Mol Ther 2006; 8: 11-6.

12. Bowen DJ, Spring B, Fox E. Tryptophan and high-carbohydrate diets as adjuncts to smoking cessation therapy. J Behav Med 1991; 14: 97-110.

13. Lancaster T, Stead LF. Mecamylamine (a nicotine antagonist) for smoking cessation. Cochrane Database Syst Rev 2000; 2: CD001009.

14. The FDA approves new drug for smoking cessation. FDA Consum 2006; 40:29.

15. Coe JW, Brooks PR, Vetelino MG, Wirtz MC, Arnold EP, Huang J, et al. Varenicline: An $\alpha 4 \beta 2$ nicotinic receptor partial agonist for smoking cessation. J Med Chem 2005; 48: 3474-7.

16. Foulds J. The neurobiological basis for partial agonist treatment of nicotine dependence: varenicline. Int J Clin Pract 2006; 60: 571-6.

\section{AUTHORS:}

1. Basudev Lenka

\section{PARTICULARS OF CONTRIBUTORS:}

1. Assistant Professor, Department of Pharmacology, KIMS, Bhubaneswar.

\section{NAME ADDRESS EMAIL ID OF THE} CORRESPONDING AUTHOR:

Dr. Basudev Lenka, Department of Pharmacology, KIMS, Bhubaneswar, Orissa.

E-mail: blenka2012@yahoo.com

Date of Submission: 10/04/2014. Date of Peer Review: 11/04/2014. Date of Acceptance: 16/04/2014. Date of Publishing: 05/05/2014. 